
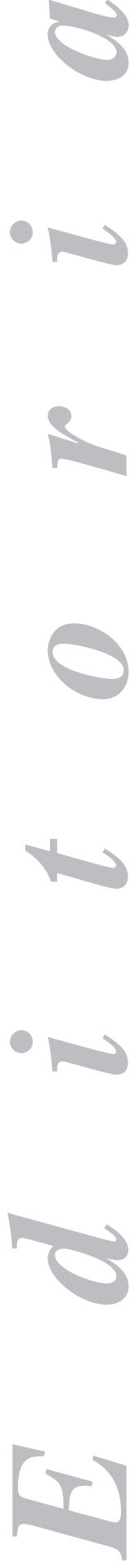

\section{Small bowel: the last frontier}

As a result of the development of endoscopic equipment, we endoscopists have played an increasingly relevant role in the diagnosis and management of esophageal, gastric, duodenal, colonic, biliary, and pancreatic conditions. The small bowel seemed out of reach, much too far from our entry doors -the mouth and the anus. The paradigm regarding this frustrating situation was obscure upper gastrointestinal bleeding. Up to $5 \%$ of patients with gastrointestinal bleeding were -and still are in many cases- repeatedly explored, admitted, and operated upon to no avail, with patients forced to cope with morbidity as inherent not only to their condition but also to such unfruitful examinations (1-3).

The advent of early push enteroscopes hardly advanced 50 to $90 \mathrm{~cm}$ (4) into the winding, distensible jejunum. With just these few centimeters, however, we increased diagnostic yield from 8 to $35 \%$. But we were still far removed from reaching the average $6.7 \mathrm{~m}$ of small bowel (5), even more so if we consider that average length beyond Treitz's angle, as reached in some enteroscopy series, was shorter than $25 \mathrm{~cm}$ (6). Radiographic explorations using a barium contrast material, including enteroclysis, are also of little help. Bleeding in excess of $0.5 \mathrm{cc} / \mathrm{min}$ is required for $\mathrm{Tc}^{99 \mathrm{~m}}$-labeled red blood cell scans to have a yield above $20 \%$, and anyway this exploration will not appropriately locate the bleeding point so that lesions may be identified during surgery (7). Arteriography, while allowing therapeutical measures, requires active bleeding during the procedure, and may be aggravated by serious complications (8).

We had to reach further then. First to describe and perform a total enteroscopy was Hiratsuka in 1971 (9), using the ropeaway procedure, only to be followed shortly afterwards by Tada (10), who reported on another total exploration using a sonde enteroscope. Both methods were time-consuming and costly in terms of complications, and thus did not become widespread; intraoperative enteroscopy remained the gold standard in the diagnosis and management of small-bowel conditions (1). With this, diagnostic accuracy increases to $75 \%$ (11) but surgical morbidity and the common development of postoperative ileus advise that this examination be restricted to patients with obscure intestinal bleeding as a last option.

The next step came a short time ago. The capsule designed and marketed by Given Imaging allows a direct, painless view of virtually the whole small bowel using a small, wireless device. The capsule currently in use is $11 \mathrm{~mm}$ in diameter and $26 \mathrm{~mm}$ in length, acquires 2 images per second, and captures and transmits around 50,000 pictures to an external recorder during its 8-hour battery life. Images are sent from this recorder to a workstation where they are reviewed by the examiner following their conversion into a video format. The capsule is minimally uncomfortable for the patient, who may be explored while out of hospital on an ambulatory 
basis. Diagnostic yield increases by 35\% (12) and reaches 65\%, thus being superior to that of push endoscopy and the rest of diagnostic techniques with only $10 \%$ of false-positive results $(12,13)$. Yield improves with proximity to the bleeding episode (less than 2 weeks), and is less effective in patients with fecal occult blood or the study of ferropenic anemia (13). It is currently considered an indication both in patients with obscure gastrointestinal bleeding and the study of Crohn's disease, non-steroidal anti-inflammatory drugs' side-effects, and familial polyposis surveillance by the European Society of Endoscopy (14).

Not all are benefits, though -a) image review lasts usually 2 hours, and interpretation is commonly difficult; b) the capsule may go rapidly past a lesion taking no pictures thereof, since its movement depends on intestinal peristaltism, which may be altered in abnormal areas $(15,16)$; and c) biopsy samples cannot (currently) be obtained, and the same goes for going back and reviewing a doubtful area, staining, raising lesions, and indeed performing therapeutic maneuvers. Finally, the capsule is contraindicated in patients with suspected stenosis, and while the development of obstructive manifestations as a capsule-related complication is uncommon, these patients require a (surgical or endoscopic) procedure to remove an impacted capsule.

In 287 b.C., Archimedes of Syracuse claimed: "Give me a place where to stand and I will move the earth". In 2001, Yamamoto applied this principle to enteroscopy, and using two fulcrum points in two balloons, one at his enteroscope's tip, the other at the overtube's end, has managed to explore the whole of the small bowel. In the present issue of our Journal, the team at Hospital Morales Meseguer, led by Dr. Pérez-Cuadrado (17), a pioneer of enteroscopy in our country (18), describe their preliminary experience using a double-balloon enteroscope with promising results.

Double-balloon enteroscopes are currently exclusively available from Fujinon in two models, the basic difference between them being their working-channel diameters $(2.2$ and $2.8 \mathrm{~mm})$. It is a $200 \mathrm{~mm}$-long endoscope with a $145 \mathrm{~cm}$-long overtube and two latex balloons (beware if patients are allergic to this material), each at the end of either tool, which are alternatively insufflated using a manometer to a pressure allowing the enteroscope or overtube to remain fixed to the intestinal wall with no damage or excessive discomfort.

The method for insertion is perfectly described by Pérez Cuadrado (17) in this paper and certainly works, as it prevents intestinal loop stretching. Such distension blocks the correct transmission of displacement force to the endoscope's tip. In addition, stabilization allows the enteroscope wide maneuverability, even when fully introduced. Double-balloon enteroscopy may be performed using an oral or anal approach, and the entire small intestine may be completely revised by combining both approaches in up to $86 \%$ of patients. This rate is slightly superior to that seen with the capsule $(79 \%)(19,20)$. The rest of the gut is explored during double-balloon enteroscopy -we should be mindful that, in push enteroscopy series, a significant amount of lesions diagnosed lied well within the reach of a gastroscope, and all segments scanned by our endoscopes require appropriate revision.

The diagnostic efficacy of double-balloon enteroscopy approaches $85 \%$, with $34 \%$ new diagnoses during the examination and as few as 5\% documented falsenegative results $(21,22)$. The remaining false-negative results correspond to capsule-identified lesions that are difficult to interpret or of little relevance (23-25). In some series, explorations with no findings had been performed in patients with a history of familial polyposis or during the surveillance of intestinal lymphomas, where even a negative exploration terminates further exams. 
However, the greatest benefit of this technique is its capability for biopsy collection, and resolving therapeutic procedures (regarding the series reported in this issue, $38 \%$ biopsies and $50 \%$ procedures). Even when surgery is needed, this may be performed using less aggressive procedures such as laparoscopy (21) as a result of endoscopic marking.

The procedure's length oscillates from 67 to 190 minutes, with a mean value around 90 minutes, and sedation is recommended. Enteroscopy has to be interrupted on occasion before a full revision of the small bowel is completed when time runs out. Discomfort extent and the duration of anesthetic time make it advisable that the oral and anal approaches be used in different days, when needed, even though both are commonly employed during the same procedure with no apparent complications. Initial route selection depends on the findings of previous examinations and is preferentially distal in Eastern series, and proximal in European series, as is the case with Pérez Cuadrado (17). Technical difficulties are associated with the absence of location marks within the small bowel, small-bowel distensibility, and the presence of post-surgical adhesions $(19,21)$.

Findings most common in a number of series include erosion and ulceration, while arterio-venous malformations followed by polyps and tumors stand out in other series. This variability partly results from demographic characteristics in the area where explorations are performed, as well as indications: confirmation and treatment of already detected lesions or initial diagnostic examination. Diagnostic yield in bleeding patients is $82 \%$, and goes down to $64 \%$ in those explored for other causes (6); only a history of previous transfusion serves as a predictive factor for a favorable outcome.

Given the complexity of double-balloon enteroscopy, which requires a second trained explorer to operate the introduction system, an operating room with radiographic equipment, and in many series an anesthesiologist in charge of sedation, capsule endoscopy understandably remains a first-choice exploration when a small-bowel study is indicated, while double-balloon endoscopy is currently reserved for therapeutic usage, and the search for lesions not diagnosed with other modalities (5).

Double-balloon enteroscopy seems safe enough, and most complications described seem related to sedation. However, a third perforation is described in the series by Pérez Cuadrado, here in a "fixed" sigmoid loop, while previous reports referred to the small bowel of a patient receiving chemotherapy for lymphoma, and an electrofulguration area in a patient with angiodysplasia (22). Feverish conditions with pain and a paralytic ileus have also been described.

To conclude, double-balloon enteroscopy is an extraordinarily attractive novel technique that, according to preliminary results, seem to be superior to other smallbowel explorations, and additionally offers an opportunity for therapeutic management. Methodological complexity currently places this technique as a second-line procedure for the study of the small intestine, but who knows what the future may bring, considering that current endoscopes are naught but prototypes, and explorers find themselves at the start of their learning curves? Anyway, according to these preliminary studies double-balloon enteroscopy seems clearly a cost-effective examination in the diagnosis and treatment of intestinal disease, so please fasten your seat belts and let us set out for a trip to places where nobody has ever been. 


\section{REFERENCES}

1. Zuckerman GR, Prakash C, Askin MP, Lewis BS. AGA technical review on the evaluation and management of occult and obscure gastrointestinal bleeding. Gastroenterology 2000; 118: 201-21.

2. Rockey DC. Occult gastrointestinal bleeding. N Engl J Med 1999; 341: 38-45.

3. Lahoyi S, Futami N. The small bowel as a source for obscure gastrointestinal blood loss. Curr Gastroenterol Rep 1999; 1: 424-30.

4. Su MY, Liu NJ, Hsu CM, Chiu CT, Chen PC, Lin CJ. Double balloon enteroscopy-the last blind-point of the gastrointestinal tract. Dig Dis Sci 2005; 50: 1041-5.

5. Gerson LB. Double-balloon enteroscopy: the new gold standard for small-bowel imaging? Gastrointest Endosc 2005; 62: 71-5.

6. Matsumoto T, Moriyama T, Esaki M, Nakamura S, Iida M. Performance of antegrade double-balloon enteroscopy: comparison with push enteroscopy. Gastrointest Endosc 2005; 62: 392-8.

7. Gutiérrez C, Mariano M, Vander Laan T, Wang A, Faddis DM, Stain SC. The use of technetium-labeled erythrocyte scintigraphy in the evaluation and treatment of lower gastrointestinal hemorrhage. Am Surg 1998; 64: 989-92.

8. Rollins ES, Picus D, Hicks ME, Darcy MD, Bower BL, Kleinhoffer MA. Angiography is useful in detecting the source of chronic gastrointestinal bleeding of obscure origin. Am J Roentgenol 1991; 156: 385-8.

9. Hiratsuka H. Endoscopic diagnosis in the small intestine. Stomach Intestine 1972; 7: 1679-85.

10. Tada M, Akasaka Y, Misaki F, Kwaie K. Clinical evaluation of a sonde-type small intestinal fiberscope. Endoscopy 1977; 9: 33-8.

11. Zaman A, Sheppard B, Katon RM. Total peroral intraoperative enteroscopy for obscure GI bleeding using a dedicated push enteroscope: diagnostic yield and patient outcome. Gastrointest Endosc 1999; 50: 506-10.

12. Triester SL, Leighton JA, Leontiadis GI, Fleischer DE, Hara AK, Heigh RI, et al. A meta-analysis of the yield of capsule endoscopy compared to other diagnostic modalities in patients with obscure gastrointestinal bleeding. Am J Gastroenterol 2005; 100: 2407-18.

13. Bresci G, Parisi G, Bertoni M, Tumino E, Capria A. The role of video capsule endoscopy for evaluating obscure gastrointestinal bleeding: usefulness of early use. J Gastroenterol 2005; 40: 256-9.

14. Rey JF, Spencer KB, Jurkowski P, Albrecht HW. ESGE guidelines for quality control in servicing and repairing endoscopes. Endoscopy 2004; 36: 921-3.

15. Tang SJ, Zanati S, Dubcenco E, Christodoulou D, Cirocco M, Kandel G, et al. Capsule endoscopy regional transit abnormality: a sign of underlying small bowel pathology. Gastrointest Endosc 2003; 58: 598-602.

16. Tang SJ, Zanati S, Dubcenco E, Monkewich G, Arya N, Cirocco M, et al. Capsule endoscopy regional transi abnormality revisited. Gastrointest Endosc 2004; 60: 1029-32.

17. Pérez-Cuadrado E, Más P, Shanabo J, Muñoz E, Ortega I, López-Martín A, et al. Enterosocpia de doble balón: estudio descriptivo de 50 exploraciones. Rev Esp Enferm Dig 2006; 98: 73-81.

18. Pérez Cuadrado E. Videoenteroscopia oral: estudio prospectivo de 30 casos. Rev Esp Enferm Dig 1996; 88: 9 15 .

19. Yamamoto H, Kita H. Double-balloon endoscopy. Curr Opin Gastroenterol. 2005; 21: 573-7.

20. Pennazio M, Santucci R, Rondonotti E, Abbiati C, Beccari G, Rossini FP, et al. Outcome of patients with obscuregastrointestinal bleeding after capsule endoscopy: report of 100 consecutive cases. Gastroenterology 2004; 126: 643-53.

21. Yamamoto H, Kita H. Enteroscopy. J Gastroenterol 2005; 40: 555-62.

22. Kaffes AJ, Koo JH, Meredith C. Double-balloon enteroscopy in the diagnosis and the management of smallbowel diseases: an initial experience in 40 patients. Gastrointest Endosc 2006; 63 (1): 81-6.

23. Appleyard M, Fireman Z, Glukhovsky A, Jacob H, Shreiver R, Kadirkamanathan S, et al. A randomized trial comparing wireless capsule endoscopy with push enteroscopy for the detection of small-bowel lesions. Gastroenterology 2000; 119: 1431-8.

24. Costamagna G, Shah SK, Riccioni ME, Foschia F, Mutignani M, Perri V, et al. A prospective trial comparing small bowel radiographs and video capsule endoscopy for suspected small bowel disease. Gastroenterology 2002; 123: 999-1005.

25. Hadithi M, Heine GD, Jacobs MA, V Bodegraven AA, Mulder CJ. A prospective study comparing video capsule endoscopy with double-balloon enteroscopy in patients with obscure gastrointestinal bleeding. Am J Gastroenterol 2006; 101 (1): 52-7. 